\title{
Compras y corrupción en el sector privado. Aplicación de las herramientas de la calidad a la gestión de adquisiciones de una organización educativa y propuestas de mejora
}

Purchase and corruption on private sector. Implementation of total quality management tools as a proposal to reduce corruption risks in organizations

Compras e corrupção no setor privado. Aplicação das ferramentas da qualidade à gestão de aquisições de uma organização educativa e propostas de melhoramento

\author{
María del Sol Ayala Flores \\ Centro de Investigación y Desarrollo \\ del Estado de Michoacán, México \\ E-mail:marisolayala01@hotmail.com
}

\author{
Bruno Ariel Rezzoagli \\ Facultad de Ciencias Económicas, Univer- \\ sidad Nacional del Litoral, Argentina. \\ E-mail:brezzoagli@fce.unl.edu.ar
}

Fecha de recepción: 13/02/2017 Fecha de aceptación: 19/05/2017

\section{Resumen}

El presente artículo aborda la problemática de la corrupción en el ámbito privado, con especial atención al proceso llevado a cabo por los diferentes tipos de organizaciones para la adquisición de recursos materiales (bienes, insumos, productos, etc.) en el marco de su giro 0 actividad habitual. Se parte de la hipótesis según la cual la falta de normas internas y de procedimientos en materia de compras a los que deban sujetarse los integrantes de una organización genera un potencial riesgo de prácticas desleales o de corrupción; por lo que se resalta la importancia de normar, unificar y organizar el comportamiento de toda organización, tomando como caso de estudio la Universidad de Durango Campus Morelia (UDCM). Atendiendo al caso de aplicación planteado,

Palabras clave

- corrupción

- compras

- estandarización

- calidad

- sector privado se propone un procedimiento general de adquisiciones para la Universidad, cuyo esquema nace del conocimiento y análisis de la información facilitada por los mismos directivos y empleados de dicha institución, de la observación directa y revisión de documentación pertinente y de la aplicación de las correspondientes herramientas de calidad: diagrama de afinidad, diagrama de 
relaciones y diagrama de árbol. Estas herramientas además de complementar el panorama que se visualiza de la organización en cuestión, permiten identificar las distintas estrategias para cumplir con el objetivo de mejorar la gestión de compras y reducir los riesgos de corrupción.

\begin{abstract}
This article deals with the issue of corruption in the private sector, focusing especially on the process carried out by different types of organizations for the purchase of material resources (goods, products, etc.). It is based on the hypothesis which states that the absence of internal regulations and procedures for members of an organization to follow means a potential risk of disloyal or corrupt practices. For this reason, the importance of dictating rules, unifying and organizing the behavior of an organization is highlighted. Taking the University of Durango Campus Morelia (UDCM) as a case study, a general purchase procedure for the University is proposed. This procedure is based on the knowledge and analysis of the information provided by the directors and employees of the institution already mentioned, from direct observation, from the review of relevant documentation and the implementation of the corresponding quality tools: affinity diagram, relations diagram and tree diagram. Apart from complementing the organization's scenario, these tools allow the identification of different strategies to achieve the aim of improving purchase management and of reducing corruption risks.
\end{abstract}

Keywords

- corruption

- purchase

- standardization

- quality

- private sector

\title{
Resumo
}

0 presente artigo aborda a problemática da corrupção no âmbito privado, com especial atenção ao processo realizado pelos diferentes tipos de organizações para a aquisição de recursos materiais (bens, insumos, produtos, etc.) no contexto da sua atividade habitual. Parte-se da hipótese de que a ausência de normas internas e de procedimentos na área das compras aos que os integrantes de uma organização devam responder gera um potencial risco de práticas desleais ou de corrupção; pelo que se salienta a importância de estabelecer normas, unificar e organizar o comportamento de toda organização, utilizando como caso de estudo a Universidade de Durango Campus Morelia (UDCM). Atendendo ao caso de aplicação apresentado, propõe-se um procedimento geral de aquisições para a Universidade, cujo esquema nasce do conhecimento e análise da informação facilitada pelos mesmos diretores e funcionários da nomeada instituição, da observação direta e revisão de documentação pertinente e da aplicação das correspondentes ferramentas de qualidade: diagrama de afinidades, diagrama de

Palavras-chave

- corrupção

- compras

- padronização

- qualidade

- setor privado relações e diagrama de árvore. Estas ferramentas além de complementar 0 panorama que se visualiza da organização estudada, permitem identificar as diferentes estratégias para cumprir com 0 objetivo de melhorar a gestão de compras e reduzir os riscos de corrupção. 


\section{Introducción}

La aceleración de los intercambios mercantiles, el proceso de mundialización de la economía y los cambios tecnológicos han modificado las formas de contratación y el comportamiento de los empresarios a la hora de intentar alcanzar los rendimientos que ofrece el mercado global (Tito-Añamuro, 2015). Liberalización de los mercados y avance tecnológico son algunas de las notas que, junto con la proliferación de fraudes corporativos, distinguen el escenario actual en el que se desenvuelven las organizaciones.

En las últimas décadas los escándalos de corrupción, además de los habitualmente protagonizados en el ámbito público gubernamental, han conmocionado al sector empresarial. Sin ahondar en los distintos casos, basta citar a Enron (una de las más grandes empresas de Estados Unidos), donde la colusión, o en otras palabras, complicidad de su alta gerencia con el despacho de auditoría Andersen generó un cúmulo de prácticas de carácter delictivo. Las consecuencias de estas acciones fueron negativas para los pequeños accionistas (perdieron sus ahorros), empleados (sus fondos de pensiones fueron técnicamente robados, puesto que obligatoriamente tuvieron que destinarlos a comprar acciones de la compañía previsiblemente destinadas a perder su valor), clientes (que junto a los proveedores resultaron engañados), y la sociedad en su conjunto, causando la falta total de credibilidad en las instituciones de regulación del sistema financiero (Kliksberg, 2004). A Enron le siguieron Merrill Lynch, Tyco, WorldCom, Health South Corp, entre otras, debilitando así la confianza del público en las corporaciones (Horngren, Datar y Foster, 2007).

Ante esta situación cobran especial interés desde nuestro punto de vista, incluso más que las cuestiones inherentes a las capacidades gerenciales de los ejecutivos, temas tales como los conflictos de intereses, la falta de normas y procedimientos, la desviación de poder, el cohecho en el sector privado, la malversación de caudales empresariales, el tráfico de influencias, el abuso de información privilegiada y las medidas a adoptar para reducir las decisiones arbitrarias de los directores de los entes económicos. Problemas que, como veremos en el presente artículo, se acentúan en las adquisiciones realizadas por las organizaciones.

En función de lo anterior, en este escrito centramos la atención en el problema de la corrupción privada y su vinculación con la ausencia de normas internas y procedimientos que propician amplios márgenes de discrecionalidad gerencial _ principalmente en el ámbito de las compras 0 adquisiciones - a través de un caso práctico en una organización privada sin fines de lucro: la Universidad de Durango Campus Morelia (UDCM), con el ánimo de conectar las deficiencias procedimentales con las potenciales prácticas desleales y de corrupción; y proponer un esquema 0 proceso general de adquisiciones en respuesta a tales potencialidades.

Atendiendo al planteamiento anterior, el marco teórico (apartado II) del presente artículo se estructura en dos grandes puntos o epígrafes. En un primer punto del marco teórico, estudiamos las prácticas organizacionales desleales o corruptas, partiendo de conceptos troncales en esta área de conocimiento como es el de «organización», haciendo hincapié en los diferentes tipos de organizaciones y por supuesto en identificar qué tipo es la UDCM. Cerramos este epígrafe con un breve desarrollo de las actuaciones organizacionales irregulares tales como el cohecho en el sector privado y la malversación de caudales empresariales y de la denominada corrupción corporativa.

En el segundo punto abordamos el tema del proceso administrativo y sus distintas etapas, así como la distinción entre procesos y procedimientos, además de la importancia de la estandarización. Asimismo, ponemos especial énfasis en los procesos administrativos de la UDCM y en la conexión de potenciales prácticas desleales 0 corruptas con la ausencia de un procedimiento de adquisiciones. 
Una vez desarrollado el marco teórico, procedemos a la aplicación de los elementos conceptuales descriptos a un caso concreto: la gestión de compras de la UDCM. Por lo tanto, comenzamos identificando con claridad el problema, indagando en sus causas, proponiendo estrategias para alcanzar el objetivo, a partir de la implementación de algunas de las nuevas herramientas administrativas de la calidad (diagrama de afinidad, diagrama de relaciones, diagrama de árbol). Finalmente diseñamos un procedimiento general de adquisiciones, planteando supuestos de aplicación así como de excepción y las distintas etapas o pasos necesarios para tal fin.

Concluimos el trabajo con los resultados esperados, las conclusiones (producto del estudio, interpretación y reflexión) y recomendaciones finales con base en el caso de aplicación presentado.

Como podemos apreciar, esta investigación resulta de gran importancia y actualidad debido a la quiebra del concepto tradicional de corrupción (como uso desviado del poder público en beneficio privado) y de los paradigmas que marcaron a varias generaciones de seres humanos, a partir de la sucesión de fraudes protagonizados por diferentes tipos de organizaciones dando origen al fenómeno conocido como corrupción corporativa, donde los directores 0 administradores juegan un papel trascendental.

Además del aporte doctrinal, este trabajo se confecciona como respuesta al caso práctico propuesto: un esquema de adquisiciones para la UDCM, que puede ser tomado como referencia por otras organizaciones (atendiendo a sus particularidades), no sólo para mejorar la eficiencia operativa sino también para evitar prácticas corruptas difíciles de detectar ante la ausencia de normas claras, en el marco del actual escenario de fraudes corporativos.

Todo ello nos lleva a plantear, oportunamente, la pregunta general de investigación: ¿Cómo afectan la falta de procedimientos y la excesiva discrecionalidad gerencial a las compras de la UDCM? y las siguientes preguntas específicas: ¿Cómo se realizan las compras de recursos materiales en la UDCM? ¿Cómo repercute la ausencia de procedimientos de adquisiciones en la generación de prácticas desleales en la UDCM? ¿Es necesaria la implementación de un procedimiento general de adquisiciones en la UDCM? Cuestionamientos que dan origen a la hipótesis de que «existe una ausencia de normas internas y de procedimientos en materia de adquisiciones a los que deban sujetarse los integrantes de la UDCM que genera un riesgo potencial de que se comentan prácticas desleales 0 de corrupción». Finalmente y como consecuencia de lo anterior, este trabajo tiene como objetivo proponer para la UDCM, ante la actual discrecionalidad gerencial, un procedimiento general de adquisiciones de los recursos materiales que contribuya a la no aparición de riesgos de prácticas desleales o de corrupción. Para ello resulta necesario: a) describir cómo la Universidad lleva a cabo sus compras, para demostrar la falta de procedimientos en esta materia; b) relacionar esa falta de procedimientos con la potencialidad de llevar a cabo prácticas desleales 0 irregulares; y 3) confeccionar una propuesta de procedimiento general de adquisiciones.

\section{Marco teórico}

\section{Organización y prácticas desleales 1.1. Concepto de organización}

Dado que el objeto del presente trabajo de investigación radica en la necesidad de proponer en la UDCM un procedimiento general de adquisiciones que contribuya en cierta medida a prevenir actuaciones corruptas, creemos conveniente comenzar escribiendo sobre el concepto de organización puesto que la Universidad de Durango es una organización que tiene una determinada estructura y lleva a cabo ciertas actividades que deben estar coordinadas y ordenadas racionalmente para cumplir con su objetivo o propósito general. 
En este sentido, la palabra organización desde un punto de vista etimológico proviene del vocablo griego organon que significa instrumento (Munch Galindo y García, 2006). Efectivamente, a través de la organización de los recursos materiales, humanos y financieros que forman un grupo social se obtendrá una mayor eficiencia.

Posteriormente a la etapa de planeación en la cual se determinan los objetivos organizacionales, resulta menester definir cuáles serán los instrumentos o medidas a utilizar para lograr estos.

No obstante lo anterior, cabe afirmar que el término organización es susceptible de dos acepciones: una designa a una entidad o grupo social, y otra se refiere a la organización como un proceso (Munch Galindo y García, 2006; Guerra Espinal, 1992).

Atendiendo a la primera acepción, una Organización es toda agrupación deliberada de personas para el logro de algún propósito específico, el cual se expresa en términos de una meta o conjunto de metas a alcanzar (Robbins y Coulter, 2000). Así se expresa la Real Academia Española, al manifestar, en su tercera acepción, que Organización es toda «asociación de personas regulada por un conjunto de normas en función de determinados fines» (RAE, 2001).

Mientras que cuando hablamos de la organización como proceso (mejor dicho como una etapa del proceso administrativo) estamos haciendo referencia a una serie de pasos consistentes en determinar las tareas a realizar, quiénes la realizarán y cómo deben agruparse para cumplir con los fines establecidos (Robbins y Coulter, 2000).

Por otra parte, el Modelo Nacional para la Calidad Total (ed. 2007) entiende a la organización como sistema, al concebirla como un ente interdepen- diente que requiere retroalimentación para optimizar su desempeño. ${ }^{1}$

Finalmente, si se analizan estos significados se puede concluir que, en esencia, todos giran en torno a la idea de una estructura, ${ }^{2}$ aunque con diferentes implicaciones.

Por lo tanto, los elementos que integran el concepto de organización son: estructura, jerarquía, sistematización, simplificación, agrupación de actividades y determinación de responsabilidades.

Así, podemos decir que la organización es el establecimiento de una estructura donde habrá de operar un grupo de personas, a través de la determinación de jerarquías y la agrupación de tareas 0 actividades, con el ánimo de lograr el máximo aprovechamiento posible de los recursos y simplificar funciones (Munch Galindo y García, 2006:113). Este es el concepto adoptado a los fines del presente trabajo.

\subsection{Tipos de organizaciones}

Existen innumerables clasificaciones de organización, cada una de las cuales responde a diferentes criterios. Nosotros, en virtud del presente trabajo, optamos por establecer una clasificación atendiendo a los siguientes aspectos:

- Según sus fines, las Organizaciones pueden ser: "sin fines de lucro» (persiguen objetivos de carácter social, deportivo 0 cultural, etc.) 0 "con fines de lucro» (es decir, a través de sus actividades pretenden obtener beneficios de carácter económico). Estas últimas reciben el nombre de empresas.

- Según la línea de mando, se dividen en: Organizaciones verticales — basadas en el principio de jerarquía, ya que los empleados necesitan la guía de sus jefes y su autorización para actuaru Organizaciones horizontales — gobernadas por

(1) Vid. Glosario del Modelo Nacional para la Calidad Total, edición 2007. (Fideicomiso Premio Nacional de Calidad, 2007).

(2) Desde este punto de vista, la organización es a una empresa lo que la estructura a un edificio en construcción, ya que la organización establece la disposición y correlación de tareas que el grupo social debe llevar a cabo para lograr sus objetivos, proveyendo la estructura necesaria a fin de coordinar eficazmente los recursos (Munch Galindo y García, 2006:111). 
equipos multidisciplinarios, dado que se suprimen la jerarquía y las fronteras entre funciones 0 departamentos - (Krajewski y Ritzman, 2000). En sentido vertical, las actividades se agrupan en función de su similitud y se habla de relaciones jerárquicas, mientras que en sentido horizontal, las actividades se agrupan en razón de un resultado concreto a obtener y se habla de procesos (Muñoz Machado, 1999).

- Según el objeto organizacional, pueden ser: públicas (son aquellas pertenecientes al sector público, cuyo objeto es satisfacer las necesidades generales) 0 privadas (no pertenecen al sector público sino a sujetos privados). Al hablar del objeto nos referimos a qué hace la Organización (Pérez López, 1996).

- Según la temporalidad, se clasifican en: «de carácter permanente» (nacen para realizar actividades que no se agotan en la concreción de un proyecto, sino que perduran en el tiempo) 0 «de carácter eventual 0 transitorio» (surgen únicamente para llevar a cabo una actividad, ya que desaparecen una vez alcanzado o cumplido el objetivo).

Por otra parte, atendiendo a la estructura organizacional y dado que la misma se refiere a la forma en que se dividen, agrupan y coordinan las tareas en el trabajo (Robbins, 2004); podemos hablar de distintas organizaciones: lineal, funcional, lineal asesorada, matricial, y por comités.

Resulta importante distinguir la estructura formal (que es la estructura organizacional en sentido estricto, es la prevista; expresa los procesos formales) de la informal (que expresa los procesos reales que surgen de la interacción entre los miembros de una Organización, tomando como base la disposición y las relaciones informales de trabajo) (Rodríguez Valencia, 1996).

\section{Organización lineal}

La organización lineal constituye la estructura más simple y más antigua, está basada en la organización de los antiguos ejércitos y en la organización eclesiástica medieval (Chiavenato, 2000).

Se caracteriza por la fuerte influencia de la autoridad central, ya que prácticamente no se delega poder. En este sentido, los niveles inferiores sólo deben cumplir las órdenes dictadas por sus superiores y reportarles periódicamente el avance y resultados de la actividad desarrollada (Rodríguez Valencia, 1993).

\section{Organización funcional}

La organización funcional es la estructura que aplica el principio de la especialización de las funciones, por lo que en este tipo de organizaciones ningún superior tiene autoridad total (lineal) sobre los subordinados, sino autoridad funcional, que es parcial y relativa y deriva de su especialidad (Chiavenato, 2001).

Existe una nítida división de trabajo y especialización de tareas, ${ }^{3}$ de manera que cada persona, desde el Director hasta el auxiliar, ejecuten el menor número de funciones (Rodríguez Valencia, 1993).

\section{Lineal asesorada (o lineal con staff)}

Se presenta una estructura lineal pero con la variante de contar con profesionales que asesoran a los directivos. El término «staff» alude a organismos que no tienen poder de decisión, sino funciones de asesoramiento (Del Prado, 1998:50).

Es decir, se combinan los dos tipos de organización: lineal y funcional, con el ánimo de aprovechar las ventajas y evitando las desventajas inherentes a cada una (Chiavenato, 2001).

Efectivamente, de la organización lineal, se conservan los órganos de línea (de ejecución)

(3) La especialización del trabajo comprende dos dimensiones: horizontal o "amplitud del puesto", que se refiere a la cantidad de tareas que contiene cada cargo, y vertical o "profundidad del puesto", que consiste en el grado de control de las tareas ejercido por el trabajador y su capacidad para tomar decisiones (Del Prado, 1998:88). 
caracterizados por la autoridad lineal y el principio jerárquico; y de la organización funcional, los órganos de staff que prestan asesoría y servicios especializados (Chiavenato, 2001).

Por lo tanto, se trata de un tipo mixto o híbrido de organización, ya que los órganos de línea están directamente relacionados con los vitales de la organización y tienen autoridad lineal sobre la ejecución de las tareas orientadas a sus objetivos, mientras que los órganos de staff (de asesoría) se hallan indirectamente relacionados con los objetivos de la Organización y carecen de autoridad lineal, sino autoridad funcional de asesoría sobre la ejecución de las tareas orientadas a esos objetivos (Chiavenato, 2001).

\section{Organización matricial}

Existe la figura de un gerente general que controla a las otras gerencias 0 departamentos especializados, ya que la organización gira en torno a proyectos y cada departamento trata distintos aspectos de estos. La forma matricial de organización selecciona a un jefe de proyecto que, a su vez, selecciona a su equipo (Odiorne, 1990), lo cual le permite a dicho jefe reducir las líneas jerárquicas departamentales y promover la eficiente implementación de estrategias (Rodríguez Valencia, 2000). ${ }^{4}$

En pocas palabras, la forma matricial es una estructura sumamente flexible, con una escasa formalización del comportamiento, una alta especialización horizontal del puesto, una tendencia a agrupar a los especialistas en unidades funcionales pero formando equipos de proyectos agrupados en base al mercado, intenso uso de los dispositivos de enlace para fomentar la adaptación y un importante grado de descentralización (Del Prado, 1998).

\section{Organización por comités}

Los comités reciben distintas denominaciones, tales como comisiones, juntas, consejos, grupos de trabajo, etc., las cuales revelan el fuerte desacuerdo que existe en cuanto a cómo llamarlos (Chiavenato, 2001).

Son cuerpos consultivos, que pueden situarse en cualquier nivel de la organización, con el objeto de reunirse para deliberar y aconsejar sobre las decisiones tomadas. Es una tendencia a la descentralización del poder. En este sentido, podemos definir «comité» como un grupo de personas cuyo cometido es la resolución de un problema o la toma de una decisión sobre una cuestión concreta (Arguedas y Nogueras, 2007).

\subsection{Prácticas desleales en las organizaciones}

Como expresamos en la introducción de este artículo, el derrumbe del «gigante» energético Enron, la caída de Arthur Andersen, el desempeño de empresas como Merrill Lynch, WorldCom, Gescartera, etc. son ejemplos concretos que reflejan importantes escándalos de corrupción en el ámbito privado. Fraudes que involucran también a los agentes de valores ${ }^{5}$ y a los despachos de auditoría que incurren en marcado conflicto de interés al asesorar a empresas que deben auditar, destacándose las prácticas de contabilidad creativa (Lozano García, 2004) con la intención de distorsionar la información presentada en los estados contables de los entes económicos.

Efectivamente, Enron poseía acciones con valor de $\$ 68$ mil millones en su máximo, no obstante llegó a valer casi nada en cuestión de meses, con lo que desaparecieron ahorros para el retiro de miles de empleados y otros accionistas. El caso de WorldCom fue similar, ya que sus acciones tuvieron un precio que alguna vez llegó a un valor máximo de mercado de $\$ 115$ mil millones, después de una cadena de

(4) Tengamos en cuenta que la palabra "estrategia" ha sido utilizada en el mundo de los negocios sólo en las últimas décadas, dado que hasta fines de la década de los cincuenta, la estrategia era vista como una variable que pertenecía exclusivamente al ámbito militar (Del Prado, 1998:29).

(5) Los agentes de valores son las personas (agentes de bolsa) o instituciones (casas de bolsa) que están directamente relacionadas con el público inversionista y con las emisoras de valores (Ortega Castro, 2008:92). 
adquisiciones que incluían a la conocida compañía telefónica MCl, pero en 2002 declaró la quiebra más grande de todos los tiempos (Berk y Demarzo, 2002).

La acusación de corrupción y la obscena manipulación de la información financiera ha sido el común denominador de estas organizaciones empresariales, lo cual puso en evidencia que no siempre los directivos u administradores actúan en representación de los intereses de los accionistas. El administrador tiene un deber genérico de lealtad frente a su principal (Bolea Bardon, 2015). La deslealtad debe ser entendida como la actuación en contra de los intereses cuya defensa nos viene confiada en virtud de un acto de voluntad de quien legítimamente es titular de los mismos (Sabán Godoy, 1991)

Por otra parte, es importante tener en cuenta que la dispersión de la composición accionarial de las compañías multinacionales que cotizan en bolsas de distintos países se convierte en una dificultad para articular un proceso de decisiones por parte de los propietarios de aquéllas (miles de pequeños accionistas) y por lo tanto, mayor resulta el grado de autonomía y de discrecionalidad con el que cuentan de hecho los ejecutivos que la dirigen (Castresana Fernández, 2004).

Tal situación, unida al comprobado fracaso del sistema de fiscalización externa de las compañías mediante los procedimientos tradicionales de auditoría (Andersen, Merril Lynch, etc.) y a través de las instituciones de control de determinadas actividades mercantiles (bancos emisores, mercado de valores, control de cambios, etc.), ha permitido la consumación de conductas delictivas de gran trascendencia y repercusión económica, prácticamente sin capacidad de interferencia 0 de reacción institucional para prevenirlas y evitarlas (Castresana Fernández, 2004).

\subsection{Corrupción corporativa}

Las herramientas creativas de contabilidad y la manipulación de la información societaria han puesto en el sector privado el foco de análisis de estas últimas décadas (Bertizzolo y Galmarini, 2013), en las que fuimos verdaderos testigos de la quiebra de conceptos tradicionales y de los paradigmas que marcaron a varias generaciones de científicos (Rezzoagli, 2006).

Existe, pues, una ruptura en la literatura especializada en temas vinculados con corrupción, a partir de la sucesión de fraudes contables protagonizados por diferentes organizaciones empresariales tales como sociedades comerciales, consultoras, despachos de auditoría, etc.; ya que dicho fenómeno dejó de considerarse exclusivo de la función pública pasando a abarcar también aquellas prácticas organizacionales que sus administradores llevan a cabo al amparo del famoso maquillaje de la información financiera y que resultan nocivas tanto para los socios de las mismas compañías como para toda la comunidad (Rezzoagli, 2005, septiembre).

Efectivamente, las prácticas corruptas han evolucionado también como consecuencia de la globalización, dado que la corrupción tradicional comprendía sólo aquellas conductas que se correspondían con la descripción de los tipos penales de cohecho y malversación de caudales públicos, mientras que la corrupción moderna opera mucho más en los mercados financieros y responde además al tráfico de influencias y al abuso de información privilegiada (Castresana Fernández, 2004).

Por su parte Argandoña (2007:2) sostiene que «el fraude, la malversación y el desfalco no son corrupción, en sentido estricto, pero la acompañan frecuentemente, y suelen incluirse también entre las prácticas corruptas, lo mismo que el nepotismo, el clientelismo, el favoritismo, el uso indebido de influencias, el abuso de poder (...) y el uso incorrecto de información privilegiada».

El Consejo de la Unión Europea (2003) define a la corrupción privada como el acto intencionado de una persona consistente en solicitar 0 recibir, directamente 0 a través de un intermediario, una ventaja indebida de cualquier naturaleza, 0 aceptar la promesa de tal ventaja, para sí mismo o para un tercero, cuando se desempeñen funciones directivas o laborales de cualquier tipo para una entidad del sector privado, a cambio de realizar 0 abstenerse 
de realizar un acto incumpliendo sus obligaciones. ${ }^{6}$ Si bien desde un punto de vista pasivo, las conductas de corrupción en el sector privado implican la obtención de ventajas indebidas por parte de empleados 0 directivos de una empresa; desde un punto de vista activo, consisten en el ofrecimiento 0 concesión de tales ventajas a quienes cumplan funciones directivas 0 laborales en organizaciones privadas (Gómez-Jara Díez, 2008).

En la denominada corrupción privada o empresarial no sólo resultan lesionados los intereses de los propietarios (accionistas) de las compañías involucradas, también el resto de los operadores en el mercado y la economía en su conjunto ya que se falsea la competencia leal, con consecuencias negativas para todos los ciudadanos.

Por último, como expresa Sabán Godoy (1991:15) el componente anímico de la corrupción es la deslealtad. Por lo tanto, podemos decir que la corrupción está estrechamente vinculada a la idea de abuso.

\section{Los procedimientos administrativos.}

Especial atención a la gestión de compras

\subsection{Concepto de proceso administrativo}

Cuando hablamos de «proceso administrativo» estamos haciendo referencia al conjunto de decisiones y actividades en marcha que realizan los gerentes en sus tareas de planificación, organización, dirección y control (Robbins y Coulter, 2000). Es decir, nos referimos a las decisiones que los gerentes adoptan y las actividades que llevan a cabo en forma continua al planificar, organizar, dirigir y controlar. Para Robbins y Coulter (2000:12):

esto significa que, cuando los gerentes hacen su trabajo (es decir, cuando desempeñan las funciones administrativas), suelen llevar a cabo sus actividades sobre la marcha y de manera continua, es decir lo hacen dentro de un proceso. No existen puntos simples y definidos de inicio o final cuando los gerentes planifican, organizan, dirigen y controlan. Cuando los gerentes «administran», es frecuente que se involucren en actividades que implican algo de planificación, algo de organización, algo de dirección, algo de control, y que tal vez ni siquiera la realicen en ese mismo orden.

\subsection{Etapas del proceso administrativo}

Todo proceso administrativo consta de cuatro etapas: planear, organizar, dirigir y controlar.

Tengamos en cuenta que las organizaciones existen para lograr un propósito, que debe ser definido con claridad por parte de la gerencia así como los medios para darle cumplimiento. Por lo tanto, la primera función que tienen a cargo los gerentes es la planificación, consistente en definir las metas, establecer una estrategia para alcanzarlas y llevar a cabo los planes para integrar y coordinar las distintas actividades (Robbins y Coulter, 2000).

Cuando hablamos de planeación, debemos distinguir: propósitos o misiones (función o tarea básica de una empresa 0 institución 0 de una parte de ésta), objetivos o metas (fines que se persiguen por medio de una actividad), estrategias (determinación de los objetivos a largo plazo de una empresa y la adopción de los cursos de acción y la asignación de los recursos necesarios para su cumplimiento), políticas (enunciados o criterios generales que orientan 0 encauzan el pensamiento en la toma de decisiones), procedimientos (son guías de acción en las que se detallan la manera exacta en que deben realizarse ciertas actividades), reglas (exponen acciones u omisiones específicas, como por ejemplo «no fumar»), programas (conjunto de metas, políticas, procedimientos, reglas, asignaciones de tareas, pasos a seguir, recursos por emplear y otros elementos necesarios para llevar a cabo un determinado curso de acción) y presupuestos (formulación en términos numéricos de resultados esperados) (Koontz y Weihrich, 2002). 
Otra responsabilidad de los gerentes es diseñar la estructura de la organización. A esta función la llamamos organización y se refiere al proceso de determinar qué tareas es necesario realizar, quién las llevará a cabo, cómo habrán de agruparse las tareas, quién rendirá cuentas a quién y en qué niveles se tomarán las decisiones (Robbins y Coulter, 2000). En otras palabras, consiste en: la identificación y clasificación de las actividades requeridas; la agrupación de las actividades necesarias para el cumplimiento de los objetivos; la asignación a un administrador dotado de autoridad de cada grupo de actividades; la estipulación de coordinación horizontal y vertical en la estructura organizacional (Koontz y Weihrich, 2002).

Por su parte, la función de dirección consiste en integrar y coordinar el trabajo de las personas que existen en toda Organización. ${ }^{7}$ Cuando los gerentes motivan a sus subordinados, dirigen las actividades de otras personas, seleccionan el canal de comunicación más eficaz 0 resuelven conflictos surgidos entre los miembros de la fuerza de trabajo, están ejerciendo la función de dirección (Robbins y Coulter, 2000).

Finalmente, la última de las funciones administrativas que llevan a cabo los gerentes es el control.

Una vez establecidas las metas (función de planificación), formulados los planes (función de planificación), determinados los arreglos estructurales (función de organización) y contratado, capacitado y motivado al personal (función de dirección), todavía es posible algo que resulte mal. Para asegurarse de que las cosas funcionen correctamente, los gerentes deben vigilar el rendimiento. El rendimiento real debe ser comparado con las metas establecidas de antemano. Si se presentan desviaciones significativas, la tarea de la gerencia consiste en lograr que el rendimiento del trabajo vuelva a la normalidad. (Robbins y Coulter, 2000:11-12)
En otras palabras, identificar las causas que originaron las fallas o desviaciones, corregirlas y adoptar acciones preventivas para que no vuelvan a ocurrir.

Consiste, pues, en la medición y corrección del desempeño a fin de garantizar el cumplimiento de los objetivos de la empresa y de los planes ideados para alcanzarlos (Koontz y Weihrich, 2002).

La función de vigilar, comparar y corregir es lo que se conoce como control, y en consecuencia, se inserta dentro del proceso administrativo, presentando características perfectamente diferenciadas según el nivel de decisión en el que opere (Rodríguez Valencia, 2003).

\subsection{Del proceso al procedimiento y la impor- tancia de la estandarización}

Los términos «proceso» y «procedimiento» suelen utilizarse como sinónimos, sin embargo el rigor científico exigido por un trabajo como éste, requiere discernir entre uno y otro.

Atendiendo a ello, debemos aclarar que un procedimiento es un proceso que se presenta por escrito, es decir, mediante la documentación de los procesos obtenemos los procedimientos y a través de éstos logramos la estandarización (Sosa Pulido, 2006).

De esta manera, la estandarización es toda actividad documentada que norma, organiza y unifica el comportamiento de toda organización; así, el manual de procedimientos de una empresa es un estándar (Sosa Pulido, 2006; Sosa Pulido, 2003).

Sin la estandarización se puede realizar el trabajo, tal y como se ha venido llevando a cabo, pero con riesgo de fallas de calidad, de productividad, que se presentan por ejemplo como más desperdicio del normal, más tiempo del necesario, piezas que pasan como buenas siendo malas, etc. (Sosa Pulido, 2003). Tengamos en cuenta que la calidad es un atributo por cumplir en los productos

(7) Cuando hablamos de dirección de empresas, debemos aclarar que la misma comprende desde las decisiones más corrientes (como elegir un argumento publicitario) a las opciones más complejas tales como una fusión o el lanzamiento de una nueva línea de fabricación. Por lo tanto podemos hablar de dirección estratégica y de dirección operacional (Carrillo de Albornoz y Serra, 2005:25). 
y servicios que una organización ofrece a sus clientes (Maya Mendoza, 2014).

Hoy en día, González Santoyo, Flores Romero, Chávez Rivera, Vargas Uribe y Tenorio González (2007) consideran que la calidad constituye un factor básico para la obtención de ventaja competitiva, por lo que la Organización debe adoptar una postura estratégica que busque calidad en todos los procesos, productos 0 servicios que permitan diferenciarla de sus competidoras, y afrontar nuevos retos desde una posición más competitiva, implicando ello lograr satisfacción del cliente (en el caso de la UDCM, alumnos ${ }^{8}$ ) a partir del desarrollo de excelencia de las operaciones en la Organización (144).

Finalmente, podemos decir que la estandarización se refleja en los procedimientos, que se definen como un conjunto de actividades detalladas - acorde al fin para que se utilicen - que muestran cronológicamente cómo se van realizando las actividades para lograr un fin determinado (Sosa Pulido, 2006).

Los procedimientos deben contener, según Sosa Pulido (2006), como mínimo los siguientes elementos: ${ }^{9}$
- Nombre del procedimiento

- Objetivo del procedimiento

- Indicadores del objetivo ${ }^{10}$ (índices numéricos que hacen posible conocer si se está cumpliendo el objetivo del proceso, ya que miden el logro del mismo). Tengamos presente que los consultores de empresas se apoyan en todas aquellas técnicas que permiten una mejor captación de los fenómenos de la realidad con objeto de formalizarlos y poder actuar sobre ellos (González Santoyo, Flores Romero, J. y Flores Romero, B., 2000).

- Descripción del procedimiento (pasos que se realizan)

- Normas del procedimiento

- Recursos necesarios para realizar el procedimiento

Además, pueden incluirse:

- Alcance (en dónde se aplica)

- Responsabilidades de los actores ${ }^{11}$

- Revisiones

- Autorizaciones

- Documentos anexos

- Documentos de referencia

- Lista de distribución

- Gráfica del proceso

(8) Hay que destacar que los "educandos" no son los únicos "clientes" del sistema educativo, ya que "en el contexto de la educación, los clientes de una organización educativa pueden ser: Educandos. Padres o tutores, Organizaciones que contratan servicios educativos; Estado Nacional, provincias, municipios cuando contrata servicios para terceros; Empleadores y futuros empleadores; Organizaciones educativas receptoras, de educandos provenientes de un nivel, diferente o inferior de formación. En un sentido más amplio, la sociedad toda es una "parte interesada" en la calidad de la educación; se asume que las necesidades y expectativas de la sociedad están representadas por el conjunto de regulaciones que se aplican a la actividad educativa. Esta lista de clientes no pretende ser taxativa y cerrada. Cada organización educativa tiene la atribución de asignar la condición de cliente a cualquier sector que reciba, directa o indirectamente, sus servicios" (IRAM, 2000:3-14). IRAM 30000-Guía para la Interpretación de la norma ISO $9001: 2000$ en la educación.

(9) IRAM (2000:55).

(10) Sobre este tema González Santoyo, Flores Romero, Chávez Rivera, Vargas Uribe y Tenorio González (2007) expresan que los indicadores permiten visualizar la evolución del proceso y sus puntos problemáticos, es decir, mostrar la estabilidad de proceso y su variabilidad; siendo básicos para la toma de decisiones. Existen indicadores clásicos relacionados con el costo (costos de operación, de materia prima, de comercialización, beneficios por unidad de negocios o globales, desviaciones respecto del presupuesto, margen de beneficio por unidad de procedencia, costos de desarrollo de producto), indicadores relacionados con la agenda (tiempo de desarrollo de producto o procesos, cumplimiento de los pedidos, tiempo de formación, las curvas de aprendizaje), e indicadores relacionados con las prestaciones (es importante considerar la cuota de mercado, la cotización de la acción, la imagen de la empresa, las quejas de los clientes insatisfechos. Las prestaciones del personal tales como cantidad producida por tiempo invertido, número de quejas de los clientes atendidos, número de sugerencias aportadas) (González Santoyo et ál, 2007:157).

(11) Los actores son aquellas personas que llevan a cabo el proceso. 


\subsection{La falta de un procedimiento de adquisi- ciones en la organización y las potenciales prác- ticas desleales 0 corruptas}

Para toda organización resulta importante contar con un procedimiento general de adquisiciones que le posibilite hacer mejores compras a menores costos, es decir, «alcanzar los objetivos y metas con menor inversión de tiempo, esfuerzos y recursos (eficiencia)» (González Santoyo, Brunet I Icart, Chagolla Farías y Flores Romero, 2003:4).

La ausencia de procedimientos a la hora de comprar y por ende efectuar el gasto correspondiente, no impide que el trabajo se haga — de hecho así suele hacerse en las organizaciones que no cuentan con ellos - pero sí que las transacciones se realicen con un potencial riesgo. Riesgo que se traduce en: mayores costos, peor financiación, mayor plazo de entrega de material adquirido, mala calidad del producto, etcétera.

Además de las posibles fallas de calidad consecuencia de la no existencia de procedimientos-, pueden también presentarse situaciones de corrupción. Tengamos presente que «compras» es un área, tal como expresan Montiel Méndez, Ruz Velázquez y Cervantes Arreola (2013), vulnerable al fraude, sobornos y mal uso de regalos. A los fines de prevenir actos de corrupción, resulta crucial identificar y evaluar los procesos organizacionales donde existe mayor probabilidad de sobornos y tomar las medidas y acciones necesarias para eliminar o minimizar dicho riesgo (Norma ISO 37001/2016).

No toda mala compra envuelve necesariamente un accionar irregular, sin embargo cabe destacar que sí existe posibilidad de que detrás de una mala adquisición haya colusión (pacto ilícito) entre el comprador (trabajador 0 empleado encargado de esa compra) y el proveedor en daño de la organización, situación que resulta muy difícil de cons- tatar si no existen parámetros claros que permitan detectar desvíos. ${ }^{12}$

Es necesario, según nuestro punto de vista, contar con procedimientos de adquisiciones que garanticen la concurrencia y la competencia entre los oferentes en un plano de igualdad de tratamiento, así como la objetividad de las decisiones adoptadas por los gerentes 0 administradores de la organización. Fijándose supuestos concretos para las tramitaciones de urgencia y las compras directas.

\section{Metodología}

Antes de comenzar a explicar los métodos y técnicas utilizados en esta investigación, debemos aclarar que por método entendemos el camino a seguir para lograr un fin determinado 0 alcanzar un objetivo (Tecla Jiménez y Garza Ramos, 1981) y que consta de varias técnicas, las cuales se conforman con un conjunto de reglas que hacen posible aplicar de forma directa y concreta los métodos.

Aplicamos el método deductivo, tomando como base conocimientos generales sobre la teoría de la organización y las prácticas de corrupción para inferir conclusiones particulares en el ámbito de las adquisiciones de la UDCM referentes a la implantación de un procedimiento general para reducir el riesgo de posibles actuaciones corruptas. También aplicamos el método analógico o comparativo, dado que el tema de la corrupción que más ha tratado la doctrina ha sido, sin lugar a discusión, el propio del sector público-gubernamental, sin embargo a pesar de ello, en el ámbito privado también hemos sido testigos de conflictos de intereses por parte de directores, tráfico de influencias, cohecho y malversación de caudales empresariales; por lo que ante determinadas situaciones podrían plantearse los remedios de uno u otro sector. 
Respecto de las técnicas aplicadas, empleamos tanto técnicas de investigación documental como técnicas de investigación directa o de campo. De las primeras, cabe mencionar la técnica de la investigación bibliográfica, es decir, consulta de libros, capítulos de obras colectivas, artículos de revistas, entre otras, con el objeto de obtener un mayor conocimiento teórico sobre los temas troncales de este artículo, tales como: concepto de organización, tipo de organizaciones, concepto de corrupción, distinción entre procesos y procedimientos administrativos, significado de estandarización, etc., que nos permita determinar el marco de referencia sobre la investigación así como la experiencia de otros investigadores sobre el tema.

De las segundas, podemos citar, por un lado, la técnica de observación directa del funcionamiento de la Universidad, la cual nos revela, a partir del cuerpo de conocimientos previamente adquirido, los posible problemas referentes a la falta de procedimientos en la UDCM y su conexión con potenciales prácticas desleales; y por otro, la técnica de la entrevista, sustentada en la conversación con el Director del Campus para conocer el quehacer cotidiano de dicha Institución educativa y poder corroborar lo observado directamente. Podemos decir, pues, que la observación nos permite recoger información, formular la hipótesis de trabajo y someter posteriormente a comprobación los datos.

Complementando lo anterior, cabe destacar que la implementación de algunas de las nuevas herramientas administrativas de la calidad (diagrama de afinidad, diagrama de relaciones, diagrama de árbol) permitió identificar con claridad el problema, indagar en sus causas, proponer estrategias para alcanzar el objetivo, y finalmente planear las actividades necesarias para tal fin.

En resumen, utilizamos el método científico, el cual se sustenta - a través de un proceso sistemático y razonado - en la hipótesis y su comprobación o desaprobación, ya que en él concluyen todos los métodos y técnicas. En suma, es lógica general (Zorrilla Arena, 1986).

\section{Caso de aplicación: adquisiciones de la universidad de durango campus morelia (UDCM)}

\section{Los procesos administrativos en la UDCM}

Como caso de estudio hemos elegido una organización privada sin fines de lucro, vertical, de carácter permanente y con una estructura lineal: la Universidad de Durango Campus Morelia (UDCM), en la que existen innumerables procesos administrativos que no constan por escrito, por lo que no se advierte la presencia de procedimientos.

Tanto la selección del personal de planta, la contratación de profesores por honorarios, las relaciones institucionales y las adquisiciones responden a la propia experiencia organizacional de la Universidad en el resto de sus campus y a la habilidad del director del campus Morelia. Dado que hablamos de la propia experiencia organizacional, hay que aclarar que ese cúmulo de experiencias, rutinas, valores, creencias, expectativas, etc., conforman lo que ha dado en llamarse, desde un punto de vista doctrinal, "cultura organizativa» (Brunet Icart, González Santoyo, Chagolla Farías y Flores Romero, 2003:80).

En lo que respecta a profesores, se cuenta con una base 0 listado muy extenso atendiendo a la colaboración de los mismos en las diferentes ofertas educativas que la Universidad desarrolla en los distintos campus. En dicha «base de datos de catedráticos», se recopila tanto su información personal (nombres y apellidos, fecha de nacimiento, nacionalidad, dirección, teléfono, e-mail, etc.) como antecedentes académicos (títulos de grado y postgrado, cursos a los que asistió, idiomas, etc.) y laborales (experiencia laboral, Institución en la que actualmente presta servicios, etcétera.).

La selección del personal de planta —en cuanto proceso dinámico que pretende encontrar a la persona que de acuerdo con sus características personales, aptitudes, motivación, experiencia, formación e intereses, constituye el candidato idóneo o más adecuado para un 
puesto de trabajo (Ortega Ávalos, 2004)— ha obedecido a criterios implementados por la Dirección del Campus, basados en el mérito y capacidad de los aspirantes; ello unido al perfil del puesto que se pretendía ocupar. ${ }^{13}$ Para ello se solicitó, oportunamente, la presentación de la documentación correspondiente acompañada de una entrevista personal con cada postulante.

En efecto, contar con las personas adecuadas que reúnan las características necesarias permitirá a la Institución alcanzar sus objetivos (González Santoyo y Flores Romero, 2004).

En este sentido, debemos comentar que

toda organización debe buscar una situación de congruencia entre las variables contextuales, tanto aquellas que afectan al individuo — personalidad, actitud, valores, educación - como las que afectan a la organización — tecnología, estilos de dirección, cultura..., y las dimensiones del puesto - variedad, autonomía, significación...-, permitiendo la existencia de esta congruencia alcanzar la eficiencia que permitirá conseguir los máximos resultados posibles con los recursos que se dispone. (González Santoyo, Brunet I Icart, Chagolla Farías y Flores Romero, 2003:126).

Por otra parte, si bien existen políticas de cobro que se proporcionan a los alumnos en el primer día de clases (donde además de los datos para realizar depósitos bancarios correspondientes a colegiaturas, se aclaran la fecha límite de pago, los recargos, así como cualquier otra información relacionada a transferencias bancarias, expedición de facturas, etc.), se carece, ante eventuales incumplimientos de pago, de procedimientos de cobro diseñados en función de los objetivos y políticas de la Universidad, al volumen de operaciones, al tipo de clientela —alumnos-, al medio donde opera, etc. ${ }^{14}$

Las relaciones institucionales tampoco se desarrollan atendiendo a un cauce formal. Entendemos que siempre existe un canal informal, pero también es necesario crear el área para agilizar la celebración de convenios de colaboración con otras instituciones educativas, centros de investigación, etcétera.

Finalmente, las adquisiciones que realiza la UDCM no podían estar ajenas a la situación antes descrita. En este sentido, las compras son autorizadas por el director del campus, y responden a solicitudes de las diferentes áreas de la Institución. No obstante, la no existencia de procedimientos escritos en esta materia tiene alcances significativos y de mayor trascendencia que en otras desde el punto de vista de la corrupción corporativa. Efectivamente, la excesiva discrecionalidad gerencial (en este caso, de la Dirección) se convierte en un terreno fértil para el desarrollo de prácticas desleales. Prácticas que pueden responder al tráfico de influencias, abuso de información privilegiada e incluso al cohecho y malversación de recursos o caudales, persiguiendo un enriquecimiento patrimonial ilícito.

\section{Aplicación de las herramientas de calidad total a la gestión de compras de la UDCM}

En los epígrafes anteriores, hemos brindado el soporte teórico correspondiente a la propuesta

(13) Tengamos presente que el llamado "análisis de puesto" es el procedimiento para determinar las obligaciones correspondientes a éstos y las características de las personas que se contratarán para ocuparlos. En otros términos, dicho análisis produce información que se usa para elaborar las descripciones del puesto (una lista de las tareas del puesto) y las especificaciones del puesto (una lista de los requisitos humanos para el puesto, es decir, los estudios, habilidades, personalidad, etc., requeridos como producto del análisis del puesto (Dessler, 2001:84).

(14) Cabe mencionar que existen distintos procedimientos generales de cobranza, por lo que podemos citar la cobranza por excepción (se establece en aquellas empresas en las que el objetivo secundario es tolerante, o sea, conservar al cliente, ya que se supone que el $70 \%$ de los clientes pagará voluntariamente y en forma oportuna, por lo cual el procedimiento se establece para el $30 \%$ de restante) y la cobranza general (debe implantarse en las empresas que tienen como objetivo secundario cobrar el dinero al 100 $\%$ de los clientes, sean buenos o malos pagadores). Obviamente, el objetivo principal de toda cobranza es cobrar oportunamente (Montaño, 1987/reimp. 2003:61 y 62). 
formulada en este apartado. Indudablemente, no podemos planear un procedimiento detallado para la gestión de compras de la UDCM si se desconocen los conceptos fundamentales de la administración de empresas o la importancia de la estandarización para evitar fallas de calidad; así como las características particulares de la organización que estamos analizando: UDCM, obtenidas de la observación directa, investigación documental y entrevistas personales con algunos de sus integrantes.

No obstante, la propuesta de procedimiento que aquí se presenta no se formula únicamente de la información obtenida en los puntos precedentes sino también de aquella que surge de la aplicación de algunas de las herramientas para la calidad total (diagrama de afinidad, diagrama de relaciones y diagrama de árbol). Las herramientas de Calidad Total potencian el involucramiento de todas las personas en la gestión por procesos (Torrell Martínez, 2014), permitiéndoles a éstas identificar las causas de los problemas y determinar las mejores soluciones para la mejora continua (Álvarez García, Fraiz Brea y Río Rama, 2012).

Efectivamente, dichas herramientas además de complementar el panorama que hemos visualizado de la organización en cuestión, nos permiten identificar las distintas estrategias para cumplir con el objetivo de mejorar la gestión de compras de la UDCM y reducir los riesgos de corrupción.

\subsection{Diagrama de afinidad}

El diagrama de afinidad se utiliza para reunir datos, tales como hechos, opiniones, ideas y problemas, y organizarlos en grupos (Tompkins, White, Bozer y Tanchoco, 2006).

En nuestro caso, nos interesa generar ideas para formular e implementar un procedimiento de adquisiciones en la UDCM, por lo que en una sesión de lluvia de ideas, se anotaron los problemas e ideas referentes a la gestión de compras: falta de criterios prefijados, ausencia de una secuencia de pasos a seguir, no existencia de una base de datos de proveedores,$^{15}$ dificultad en la rendición de cuentas, etc., y se agruparon bajo determinados títulos.

Los títulos elegidos para mejorar la gestión de compras de la UDCM fueron: "falta de manual de procedimientos» $y$ «potenciales prácticas desleales 0 corruptas».

En función de ello la siguiente figura presenta un diagrama de afinidad para hacer más eficiente la gestión de compras a partir de la implementación de un procedimiento general.

Figura 1. Diagrama de afinidad

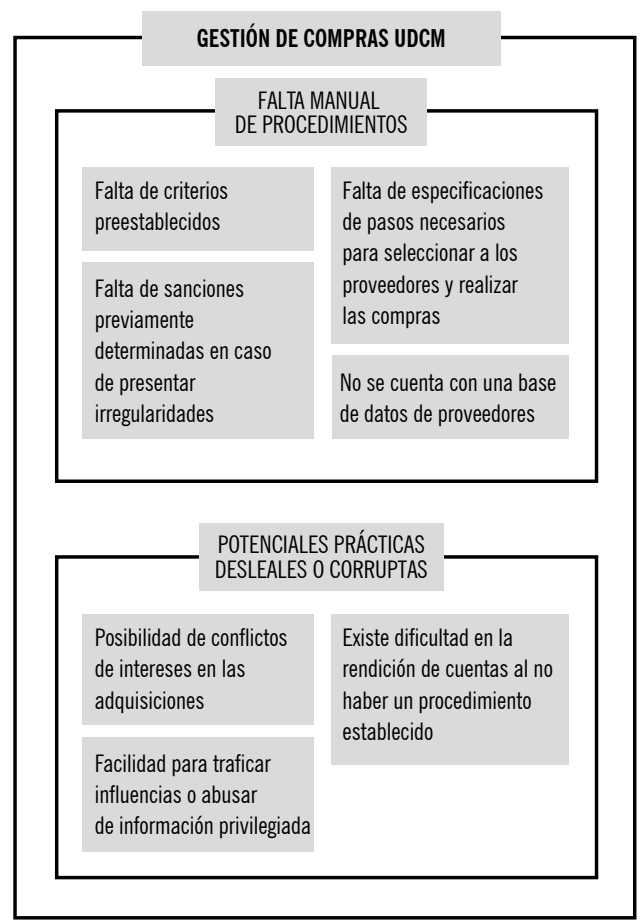

Fuente: elaboración propia

(15) Se elabora listado de proveedores, indicando: nombre, característica de producción (industrial/ artesanal), estructura de costos y precios, participación en el mercado, sistema de ventas (contado/a crédito), localización, etc. Se intenta determinar la estructura del mercado -monopolio, competencia o situación intermedia- (Miranda Miranda, 2005:101). 


\subsection{Diagrama de relaciones}

Una herramienta que se utiliza, junto con el diagrama de afinidad, en la planificación general del ciclo de mejora de la calidad es el denominado diagrama de relaciones.

Efectivamente, el diagrama de relaciones determina qué idea tiene influencia sobre otra, representando esta relación mediante una flecha en la dirección de la influencia; de tal forma que las ideas unidas por flechas de este tipo conforman un gráfico que puede ser interpretado identificando aquellas ideas que tienen las mayoría de las flechas saliendo de ellas 0 aquellas ideas que tienen la mayoría de las flechas entrando en ellas. En definitiva, busca identificar las distintas categorías en las que pueden agruparse las ideas representadas (Vilar Barrio, Gómez Fraile y Tejero Monzón, 1998).

Figura 2. Diagrama de relaciones

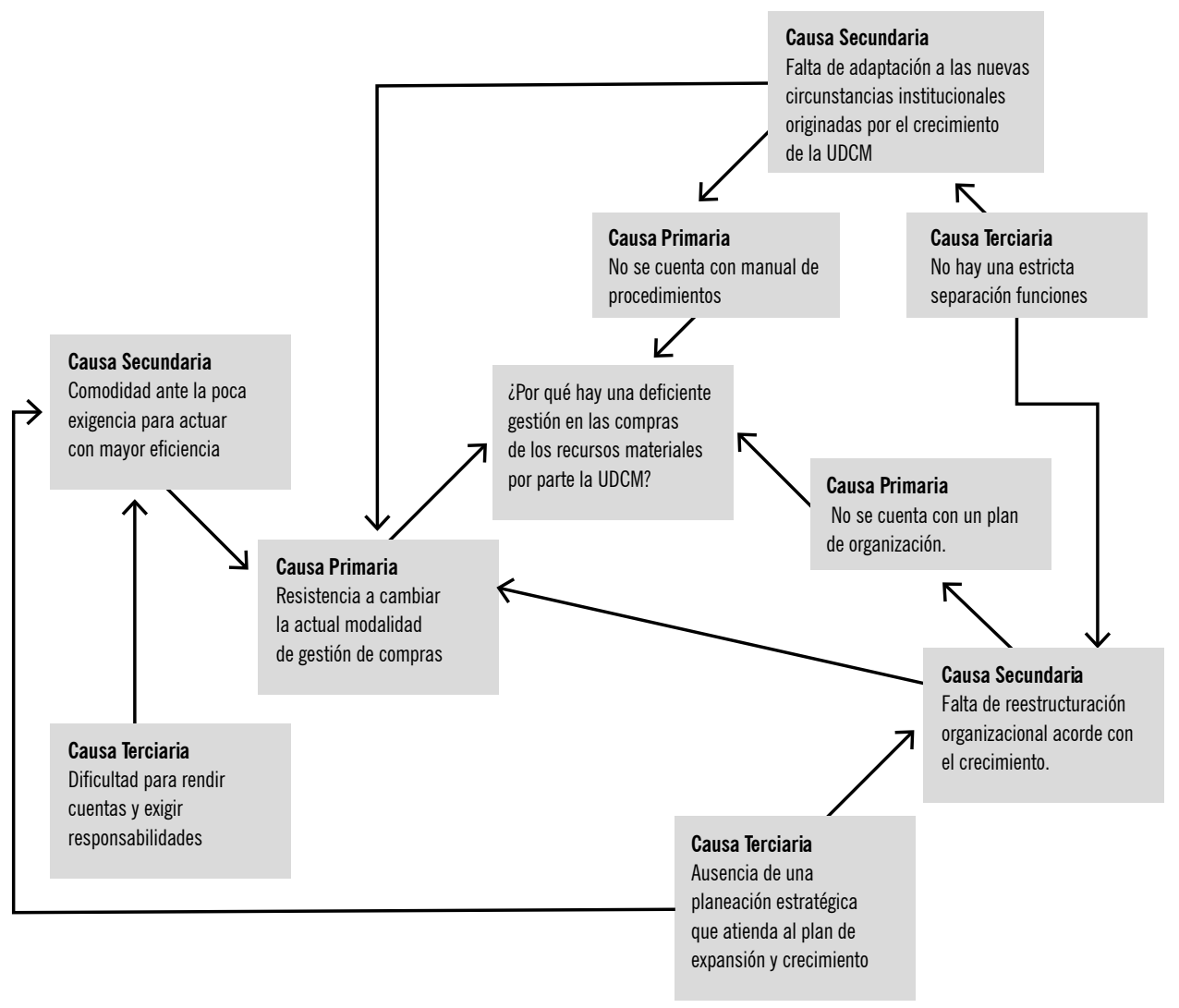

Fuente: elaboración propia 
Como podemos observar, una vez detectado con claridad el problema, se procedió a indagar en las causas que motivaron esa deficiente gestión de compras.

Para ello se elaboró un diagrama de relaciones (Figura 2), que permitió conocer las causas primarias (no se cuenta con un manual de procedimientos, resistencia al cambio, no se cuenta con un plan de organización), las causas secundarias (comodidad ante la poca exigencia para actuar con mayor eficiencia, falta de adaptación a las nuevas exigencias institucionales originadas por el crecimiento de la UDCM, falta de reestructuración organizacional acorde con el crecimiento) y las causas terciarias (dificultad para rendir cuentas y exigir responsabilidades, no hay una estricta separación de funciones, ausencia de una planeación estratégica que atienda al plan de expansión y crecimiento).

Además existe una estrecha relación entre las distintas causales: causa-efecto. Efectivamente, el continuar dirigiendo la universidad como una pequeña empresa contribuyó a la falta de reestructuración y adaptación de la organización a las nuevas necesidades y exigencias derivadas del crecimiento, lo cual se ve reflejado en la ausencia de un manual de procedimientos con criterios claros para seleccionar a los proveedores y realizar las compras, así como en la no existencia de un plan de organización.

\subsection{Diagrama de Árbol}

Se trata de una técnica 0 herramienta que hace posible visualizar de forma conjunta las distintas alternativas o medios a implementar para alcanzar una meta o dar solución a un determinado problema.

Como podemos apreciar, el diagrama de árbol se utiliza para desarrollar gráficamente todas las actividades que deben cubrirse para alcanzar un determinado objetivo (Fariña Gómez y González González, 1998). 
Figura 3. Diagrama de árbol

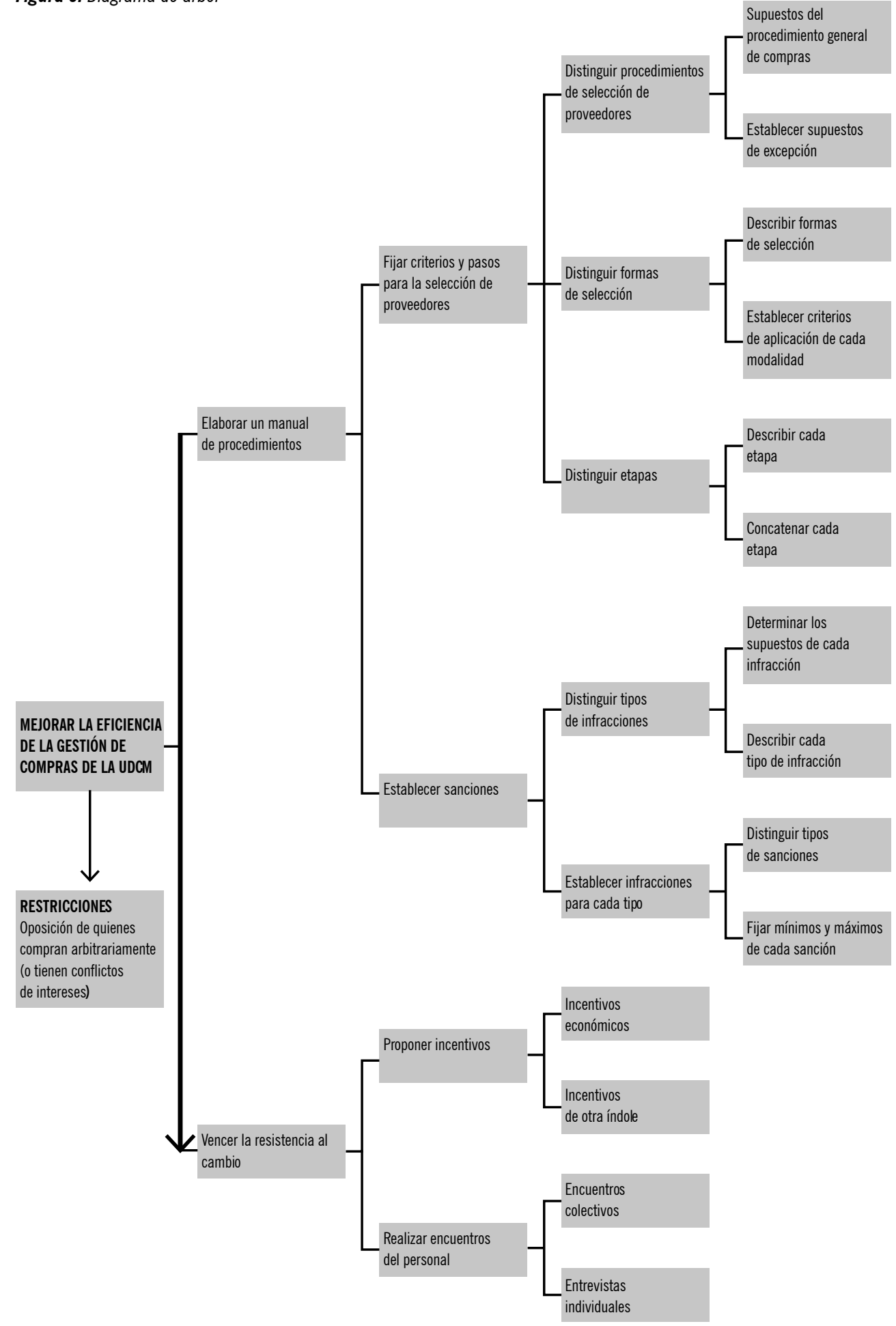

Fuente: elaboración propia 


\section{Propuesta de un procedimiento general de adquisiciones}

El procedimiento de compras vendría a ser el cauce de formación de la voluntad de comprar por parte de la UDCM con determinado proveedor representado en una serie de pasos concatenados.

El procedimiento que proponemos consta de los siguientes elementos:

- Nombre: Procedimiento general de adquisiciones - Objetivo: Establecer los lineamientos y describir las acciones a realizar para la adquisición de bienes, insumos 0 productos requeridos por las diferentes áreas de la Universidad, mediante un esquema que asegure la selección de la mejor oferta en su relación precio-calidad y la recepción en tiempo y forma de aquellos.

\section{- Indicadores del objetivo:}

- Bienes y productos recibidos (recepcionados) de conformidad (porcentaje de bienes y productos recibidos de conformidad respecto del total de órdenes de compras)

- Reducir el costo de los materiales adquiridos (porcentaje de desviaciones respecto al presupuesto).

- Bienes y productos recibidos (recepcionados) en el tiempo pactado con proveedor (porcentaje de bienes y productos recibidos en la fecha pactada con el proveedor respecto del total de órdenes de compras)

- Alcance: se aplica en todas las áreas de la Universidad.

- Descripción del procedimiento: La redacción completa y detallada del procedimiento se realiza en el punto IV.5 de este trabajo.

- Responsabilidades de los actores: El jefe de unidad 0 área que solicite la adquisición de recursos materiales y la persona por él designada para efectuar la compra serán responsables directos por tal operación. Las responsabilidades a aplicar podrán ser de carácter disciplinario (suspensión, separación del cargo), así como de carácter civil (indemnizatoria) o penal, según corresponda.
- Revisiones: La revisión de cada adquisición estará a cargo del Contador del Campus.

- Autorizaciones: La autorización para realizar cada operación será del Director del Campus.

- Recursos necesarios para realizar el procedimiento: Se requiere contar con las correspondientes partidas presupuestarias.

- Gráfica del proceso: La secuencia lógica del proceso de adquisiciones se puede observar en la Figura 4.

Es importante contar además con una base de proveedores confiable, tanto en materia prima como en componentes y servicios, así como establecer un proceso permanente de evaluación y mejora continua de los proveedores. Una vez que los proveedores han demostrado ser capaces de cumplir con los requerimientos de UDCM se incorporan a la lista de proveedores actuales. De esta forma, ello no sólo contribuye al procedimiento general, sino en especial al procedimiento de excepción ya que permite identificar a proveedores (y evaluarlos) de cara a agilizar la compra sin descuidar la calidad del material y el costo del mismo, evitando además que exista colusión entre quien realice la compra por parte de la UDCM y el proveedor.

\section{Supuestos de aplicación y de excepción}

Como toda regla general, dicho procedimiento debe ser respetado en cada una de las compras que de manera ordinaria la UDCM vaya realizando para el correcto desarrollo de sus actividades.

Sin embargo, como todo procedimiento general, tiene también sus excepciones: cuando el monto de la compra sea inferior a cierto importe 0 situaciones de urgencia que podrían comprometer el correcto funcionamiento de la Universidad. Es decir que por razones cuantitativas o cualitativas, podría no seguirse el procedimiento ordinario de compras, y llevar a cabo el denominado procedimiento de excepción consistente en la compra directa. 
Dichas alternativas que se presentan en la gráfica del procedimiento general de adquisiciones de la UDCM (Figura 4).

\section{Descripción del procedimiento general}

El procedimiento general de adquisiciones comprende una serie de etapas que van desde la justificación de la necesidad de comprar y posterior verificación presupuestaria hasta la selección del proveedor, compra del material y correspondiente evaluación. Dicho procedimiento se activa a partir de la necesidad de adquirir un determinado material, situación que debe ser justificada a través del llenado de una requisición interna por parte del área (que tenga dicha necesidad) y elevado a Dirección para su autorización. Una vez autorizada, dicha requisición se remite al área de contabilidad donde se verifica la existencia de partida presupuestaria para tal erogación. Si no hay partida contemplada en el presupuesto semestral de la Universidad, no procede la compra hasta que no se tramite una ampliación de crédito presupuestario a la Dirección General de Contabilidad (de todos los campus) en Durango.

Si existe partida presupuestaria, se procede a la realización de la compra atendiendo a dos circunstancias: si el monto de la transacción no excede de $\$ 3000$ o si es mayor a dicho importe.

Cuando el importe de la compra no supere la cuantía antes señalada, se procederá a la compra directa a partir de la consulta de la base de proveedores, de cara a agilizar las operaciones en función de la dinámica del mercado.

Si dicho importe excede de $\$ 3000$ se procederá a la elaboración del documento de especificaciones técnicas del material o producto, con el objeto de enunciar las características principales del mismo para solicitar cotizaciones de por lo menos tres proveedores.
Una vez recibidas las cotizaciones, se procederá al análisis de las propuestas con el objeto de seleccionar al proveedor que haya presentado la mejor oferta. Cabe aclarar que por formas de selección entendemos las distintas modalidades para optar por uno u otro proveedor (atendiendo al precio del producto 0 a un conjunto de factores - precio, calidad, plazo de financiación, garantía, etcétera.).

Por lo tanto, en los casos de productos o materiales cuyas características están bien definidas (no pudiendo haber diferencias respecto a éstas entre las ofertas presentadas por uno u otro proveedor), la selección recaerá en aquel proveedor que haya presentado la oferta cuyo precio sea menor (modalidad denominada subasta); mientras que si se trata de productos con características generales pero que pueden variar aquellas (ya que existe cierto margen atendiendo a su empleo 0 uso), la selección del proveedor obedecerá a la elección de la mejor oferta atendiendo a precio, plazo de financiación, calidad técnica, servicio postventa (modalidad denominada concurso).

Este procedimiento de selección del proveedor tiene sus excepciones, tal como se ha comentado en el subtema anterior, atendiendo a razones de urgencia 0 imprevistos que hacen necesaria la adquisición del material para no interrumpir el normal desenvolvimiento de la Universidad, situación que debe estar debidamente justificada (explicar los motivos).

Seleccionado el proveedor, se emite la correspondiente orden de compra (se envía al proveedor seleccionado). Una vez que el proveedor envía los bienes y productos, se procede a controlar los materiales recibidos y cotejar la factura contra remito y contra orden de compra. Posteriormente, se realiza el pago correspondiente (según las condiciones estipuladas con el proveedor). Finalmente, se procede al reporte de operación y posteriormente a la evaluación del servicio y materiales adquiridos. 
Figura 4. Procedimiento general de adquisiciones

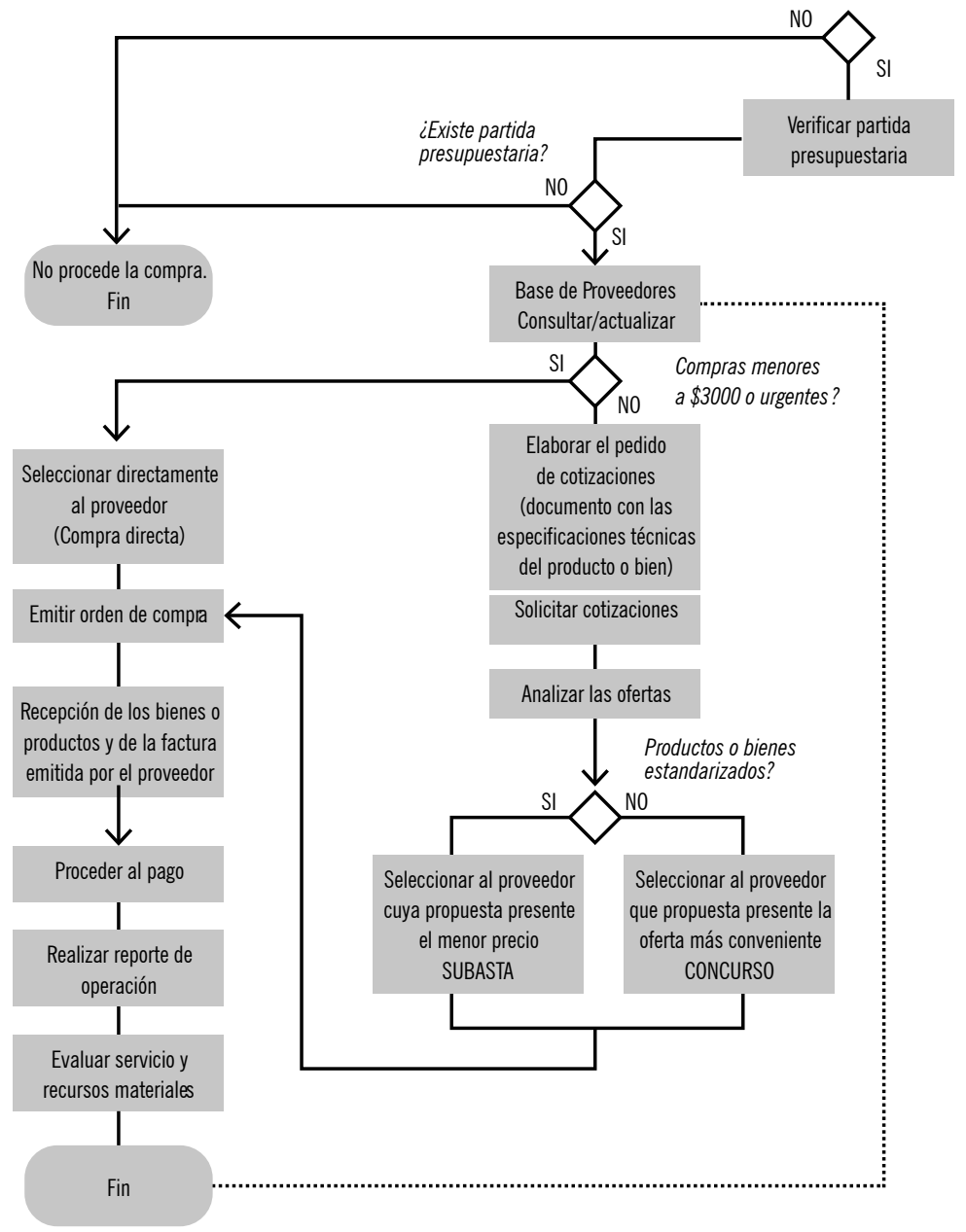

Fuente: elaboración propia

\section{A modo de reflexión}

A lo largo de estas páginas hemos citado algunos ejemplos de prácticas corruptas en el sector privado, destacando la ruptura del concepto tradicional de corrupción como «abuso del poder público en beneficio privado» y la presencia de esta en el mundo de los negocios entre particulares. De allí la importancia que tiene para las propias organizaciones establecer pautas de comportamiento y procedimientos a los que deban sujetarse sus integrantes en sus actuaciones, lo cual contribuye a mejorar el desempeño organizacional y facilitar el control tendiente a verificar si las gestiones realizadas respetaron los parámetros establecidos, desincentivando la comisión de posibles actos desleales 0 de corrupción difíciles de detectar si dichas normas internas no existieran. 
Las acciones internas que las organizaciones deben adoptar para prevenir la corrupción no pueden presentarse de forma aislada (como un fin en sí mismo) sino que deben insertarse en los distintos procesos que hacen a su normal desenvolvimiento. Una función 0 área de la organización vulnerable al soborno es, por la relación con los proveedores y los recursos involucrados, compras; resultando en consecuencia importante fijar reglas que garanticen, cuando se den determinados supuestos, concurrencia y competencia de los oferentes y el respeto por parte de los gerentes 0 administradores del principio de objetividad en la toma de sus decisiones (selección del proveedor y compra del bien o producto).

Atendiendo a tales consideraciones, este artículo aporta un caso de estudio donde se propone un procedimiento general de adquisiciones en una organización del sector privado (UDCM) así como la utilización de las herramientas de la calidad con el objetivo de involucrar a todos sus integrantes en la gestión por procesos.
La aplicación de las herramientas de la calidad permitió a los propios integrantes de la organización en cuestión identificar las causas de los problemas en la gestión de compras (causas primarias: no contar con un manual de procedimientos, resistencia al cambio, carencia de un plan de organización; causas secundarias: comodidad ante la poca exigencia para actuar con mayor eficiencia, falta de adaptación a las nuevas circunstancias originadas por el crecimiento de la organización, falta de reestructuración organizacional acorde con el crecimiento; causas terciarias: dificultad para rendir cuentas y exigir responsabilidades, la ausencia de una estricta separación de funciones y la falta de una planeación estratégica que atienda al plan de expansión y crecimiento) y determinar las soluciones para su mejora, destacándose entre ellas la propuesta de carácter procedimental que en este escrito describimos para las adquisiciones de la Universidad.

\section{Referencias bibliográficas}

- Álvarez García, J., Fraiz Brea, J.A., y Río Rama, M. (2012). Grado de utilización de las herramientas de calidad en el sector de alojamiento turístico español. Revista de turismo y patrimonio cultural, 10(5), 495-510. - Argandoña, A. (2007). La Corrupción y las Empresas. Ocasional Paper, ISE Business School. Universidad de Navarra. Recuperado en Enero 2017 de http://www.iese.edu/ research/pdfs/0P-07-21.pdf

- Arguedas, R., y Nogueras, M.T. (2007). Planificación, Dirección, y Gestión Financiera de empresas turísticas. Madrid: Editorial Universitaria Ramón Areces.

- Berk, J., y Demarzo, P. (2002). Finanzas Corporativas. México: Pearson Educación.
- Bertizzolo, M.E., y Galmarini, L. (2013). El fraude corporativo en la legislación argentina: entre las normas y la realidad. XII Congreso Argentino de Derecho Societario y VIII Congreso Iberoamericano de Derecho Societario y de la Empresa. Recuperado en Enero 2017 de: https://repositorio. uade.edu.ar/xmlui/bitstream/handle/123456789/1100/CDS12030545. pdf? sequence $=$ 1yisAllowed $=y \quad$ el 10 de abril de 2017.

- Bolea Bardon, C. (2015). Deberes del administrador y prácticas de Kick-Back. Revista Electrónica de Ciencia Penal y Criminología, 17-17, 1-31. Recuperado el 04 de abril de 2017 de http://criminet. ugres/recpc/17/recpc17-17.pdf

- Brunet Icart, I., González Santoyo, F., Chagolla Farías, M., y Flores Ro- mero, B. (2003). Las organizaciones y la gestión del cambio. Morelia: Universidad Michoacana de San Nicolás de Hidalgo-Universitat Rovira I Virgili-FeGoSa Ingeniería administrativa. - Carrillo de Albornoz y Serra, J.M. (2005). Manual de autodiagnóstico estratégico. Madrid: ESIC.

- Castresana Fernández, C. (2004). Corrupción, globalización y delincuencia organizada. En N. Rodríguez García y E. Fabián Caparrós (Coord.), La corrupción en un mundo globalizado: análisis interdisciplinar (pp. 213-226). Salamanca, España: Ratio Legis.

- Chiavenato, I. (2000). Introducción a la teoría general de la Administración (5ta. edición traducida al español por Germán Alberto Villamizar). México: Mac Graw Hill. 
- Chiavenato, I. (2001). Administración. Teoría, proceso y práctica (3era. edición traducida al español por Germán Alberto Villamizar). Bogotá: Mac Graw Hill.

- Consejo de la Unión Europea (2003). Decisión Marco 2003/568/ JAl del Consejo, de 22 de julio, relativa a la lucha contra la corrupción en el sector privado. Diario Oficial de la Unión Europea, L (192, 31 de julio), 54-56.

- Del Prado, L. (1998). Dirección estratégica. Buenos Aires: Fundación OSDE.

- Dessler, G. (2001). Administración de personal (8va. edición). México: Pearson Educación.

- Fariña Gómez, B., y González González, Y. (1998). Gestión estratégica de la calidad. Herramientas una aplicación en el campo sanitario. Anales de estudios económicos y empresariales, 13, 275-316.

- Fideicomiso Premio Nacional de Calidad (2007). Glosario del Modelo Nacional para la Calidad Total. México: Fideicomiso PNC.

- Gómez-Jara Díez, C. (2008). Corrupción en el sector privado: ¿competencia desleal $\mathrm{y} / 0$ administración desleal? Revista de las Facultades de Derecho y Ciencias Económicas y Empresariales, 74, 225-243.

- González Santoyo, F., y Flores Romero, B. (2004). Planeación de recursos humanos. En M. Valverde Aparicio, F. González Santoyo, B. Flores Romero y M. Chagolla Farías (Eds.), La gestión de los recursos humanos: enfoques para México. Morelia: Universidad Michoacana de San Nicolás de Hidalgo-Universitat Rovira I Virgili-FeGoSa Ingeniería administrativa.
- González Santoyo, F., Brunet I Icart, I., Chagolla Farías, M., y Flores Romero, B. (2003). Diseño de empresas de orden mundial. Morelia: Universidad Michoacana de San Nicolás de Hidalgo-Universitat Rovira I Virgili-FeGoSa Ingeniería administrativa.

- González Santoyo, F., Flores Romero, B., Chávez Rivera, R., Vargas Uribe, G., y Tenorio González, A. (2007). La calidad en la empresa y la importancia en el posicionamiento. En F. González Santoyo, B. Flores Romero y G. Vargas Uribe (Eds.), Modelos y estrategias para el desarrollo. Morelia: CIDEM-FeGoSa Ingeniería administrativa-Sociedad Mexicana de Geografía y Estadística. - González Santoyo, F., Flores Romero, J. J., y Flores Romero, B. (2000). La incertidumbre en la evaluación financiera de las empresas. Morelia: FeGoSa Ingeniería administrativa-Universidad Michoacana de San Nicolás de Hidalgo, Morelia.

- Guerra Espinal, G. (1992). Manual de administración de empresas agropecuarias (2da. Edición) San José, Costa Rica: Instituto Interamericano de Cooperación para la Agricultura (IICA).

- Horngren, C., Datar, S., y Foster, G. (2007). Contabilidad de costos. Un enfoque gerencial (12da. Edición traducida al español). México: Pearson Educación.

- Instituto Argentino de Normalización (IRAM). (2000). Norma IRAM 30000. Guía de Interpretación de la Norma ISO 9001 en la Educación. Buenos Aires: IRAM.

- International Organization for Standardization (ISO). (2016). Norma 37001: Anti-bribery management systems.
- Kliksberg, B. (2004, 28 de marzo). Los escándalos empresariales demostraron que hacen falta herramientas para lograr gerentes honestos. Diario La Nación, Buenos Aires. Recuperado de http://www.lanacion. com.ar/586844-los-escandalosempresariales-demostraron-quehacen-falta-herramientas-paralograr-gerentes-honestos

- Koontz, H., y Weihrich, H. (2002). Administración: una perspectiva global (11ma. Edición traducida al español por E. Mercado González). México: Mc Graw Hill.

- Krajewski, L., y Ritzman, L. (2000). Administración de operaciones: Estrategia y análisis (5ta. Edición). México: Pearson Educación.

- Lozano García, M.B. (2004). Las debilidades del gobierno corporativo en los casos de corrupción: el papel del Consejo de Administración. En N. Rodríguez García y E. Fabián Caparrós (Coord.). La corrupción en un mundo globalizado: análisis interdisciplinar (pp. 41-58). Salamanca, España: Ratio Legis.

- Maya Mendoza, J. (2014). Método para lograr la calidad en las organizaciones. Punto de Vista, 8, 77-100. - Miranda Miranda, J.J. (2005). Gestión de proyectos. Identificación, formulación, evaluación financieraeconómica-social-ambiental (5ta. Edición). Bogotá: MM editores.

- Montaño, A. (1987). Administración de la cobranza. Programación y control. México: Trillas.

- Montiel Méndez, 0., Ruz Velázquez, I., y Cervantes Arreola, D. (2013). Corrupción privada: una aproximación en tres departamentos de compras de la industria maquiladora en México. Global Conference on Business and Finance Proceedings, 8(2), 1495-1507. 
- Munch Galindo, L., y García, J. (2006). Fundamentos de Administración (7ma. Edición). México: Trillas.

- Muñoz Machado, A. (1999). La gestión de calidad total en la Administración Pública. Madrid: Ediciones Díaz Santos.

- Odiorne, G. (1990). El lado humano de la dirección. Madrid: Ediciones Díaz de Santos.

- Ortega Ávalos, M. (2004). Selección. En M. Valverde Aparicio, F. González Santoyo, B. Flores Romero y M. Chagolla Farías (Eds.). La gestión de los recursos humanos: enfoques para México. Morelia: Universidad Michoacana de San Nicolás de Hidalgo-Universitat Rovira I Virgili-FeGoSa Ingeniería administrativa.

- Ortega Castro, A. (2008). Introducción a las finanzas (2da. Edición). México: Mac Graw Hill.

- Pérez López, J.A. (1996). Fundamentos de la dirección de empresas. Madrid: Rialp.

- Real Academia Española (2001). Diccionario de la Lengua Española (22da. Edición). Madrid: RAE.

- Rezzoagli, B. (2005, 13 de junio). Los códigos de ética respecto de la corrupción. El Financiero, México, 13A.
- Rezzoagli, B. (2005, 1 de septiembre). El estigma de la corrupción lo llevaban a cuestas los políticos, ahora lo comparten los empresarios. El Financiero, México, 10A.

- Rezzoagli, B. (2006). Corrupción en el sector privado: prácticas desleales dentro de las empresas. Matrícula de Honor, 2, 177-184.

- Robbins, S., y Coulter, M. (2000). Administración (6ta. Edición). México: Pearson Educación.

- Robbins, S. (2004). Comportamiento organizacional (10ma. Edición). México: Pearson Educación.

- Rodríguez Valencia, J. (1993). Teoría de la administración aplicada a la educación. México: Ediciones contables y administrativas.

- —_ (1996). Introducción a la administración con enfoque de sistemas. México: ECASA.

- — (2000). Administración con enfoque estratégico. México: Trillas. - - (2003). Sinopsis de auditoría administrativa (8va. Edición). México: Trillas.

- Sabán Godoy, A. (1991). El marco jurídico de la corrupción. Madrid: Civitas.

- Sosa Pulido, D. (2003). Manual de Calidad Total para operarios. México: Limusa Noriega Editores.
- (2006). Administración por Calidad. Un modelo de calidad total para las empresas (2da edición). México: Limusa Noriega Editores.

- Tecla Jiménez, A., y Garza Ramos, A. (1981). Teoría, Métodos y Técnicas en la Investigación social (13ra. Edición). México: Ediciones del Taller abierto.

- Tito-Añamuro, J. (2015). Corrupción privada: un estudio de la ausencia de reglas de derecho privado, desde el caso Interbolsa. Vniversitas, 131, 433-466.

- Tompkins, J., White, J., Bozer, Y., y Tanchoco, J. (2006). Planeación de instalaciones (3era. edición traducida al español). México: Editorial Thomson. - Torrell Martínez, F. (2014). La excelencia empresarial: las herramientas de calidad total como motor para la gestión del cambio. Revista de Contabilidad y Dirección, 19, 11-28. - Vilar Barrio, J.F., Gómez Fraile, F., y Tejero Monzón, M. (1998). Las 7 nuevas herramientas para la mejora de la calidad (3era. Edición). Madrid: Fundación Confemetal.

- Zorrilla Arena, S. (1986). Introducción a la Metodología de la Investigación (4ta. Edición). México: Ediciones 0céano.

\section{Registro bibliográfico}

Ayala Flores, M.S., y Rezzoagli, B.A. (2017). Compras y corrupción en el sector privado. Aplicación de las herramientas de la calidad a la gestión de adquisiciones de una organización educativa y propuestas de mejora. Revista Ciencias Económicas, 14(01), 75-98. 